\title{
ALAT PEMANTAU KENDARAAN BERBASIS GPS DENGAN FITUR LOKAL DAN SMS PINTAR
}

\author{
Teguh Wibowo \\ Sekolah Tinggi Teknologi Adisutjipto \\ Jl Janti Blok R Lanud Adisutipto, Yogyakarta \\ teguhwibowo76@yahoo.co.id
}

\begin{abstract}
Nowadays, the development of the automotive industry in Indonesia is increasing followed by high number of motor vehicle theft. In order to reduce the motor vehicle theft case, a Global Positioning System (GPS) based instrument in motor vehicle is investigated to monitor the location of vehicles. This instrument will be run if there are a phone signal from provider and GPS signal from satellite. The method is that the owner sends a text to the destination number installed in the instrument. There are some codes needed to be paired to the instrument. If the code is matched, instrument will reply the text automatically based on the program installed in the instrument. This instrument has many advantages, such as could give the location accurately with an error less than 5 meters, could turn off the vehicle, could give an information if the vehicle is stolen, and also could record the conversations while the vehicles are in use. This instrument is also improved by installing the local language (Indonesian) and features which meet the owner requirements.

Generally, it could be concluded that this instrument really helps the rider or owner from motor vehicle theft. Good response and accurate location given by the instrument verified by the finding of
\end{abstract}

lost vehicle showed that this instrument could be applied and important if it is applied in the motor vehicles.

Keywords : Tracker, GPS, SMS

\section{Pendahuluan}

Dengan pertumbuhan dunia otomotif terutama kendaraan bermotor yang sangat pesat di wilayah Indonesia ternyata diikuti pula banyaknya kejadian kehilangan kendaraan bermotor. Apakah karena dicuri atau kasus penggelapan oleh penyewa kendaraan, hal ini menjadi inspirasi penulis untuk mengembangkan sebuah alat pemantau posisi kendaraan berbasis GPS (Global Positioning System). Sejarah GPS awalnya dibuat untuk kebutuhan militer AS kemudian dibuat dan disediakan untuk penggunaan komersial, GPS menggunakan serangkaian satelit yang memungkinkan penerima di bumi untuk mendapatkan sinyal posisi dengan akurat. Sebuah penerima GPS menghitung posisi menggunakan sinyal-sinyal dari tiga atau lebih satelit GPS. Nilai ini kemudian 
berubah menjadi lintang, bujur, kecepatan, ketinggian dan penanggalan, kemudian ditampilkan di peta untuk pengguna.

Untuk pengiriman informasi data dari alat tracker ke pemilik kendaraan menggunakan GSM (Global System for Mobile) adalah sebuah teknologi komunikasi selular yang bersifat digital, melalui teknologi ini GPS bisa mengirim data ke HP kita. Dilakukan dengan cara mengirim kode perintah sms ke no GSM yang ada di GPS Tracker. Format perintahnya ada 2, yang pertama GPS akan membalas dalam bentuk peta langsung di Handphone, Komputer dan yang kedua GPS akan membalas dalam bentuk koordinat, kecepatan, status satelit terkoneksi atau tidak.

Menggunakan GPS tracker banyak keuntungannya, yaitu digunakan untuk memantau dan melacak posisi objek apapun di planet ini dengan tepat2, termasuk perlindungan terhadap manusia dan barang-barang penting seperti perhiasan dan barang berharga. GPS pelacak untuk mengetahui posisi dapat dilakukan secara terus menerus, menyimpan data dengan menggunakan suatu sistem dengan metode yang canggih.

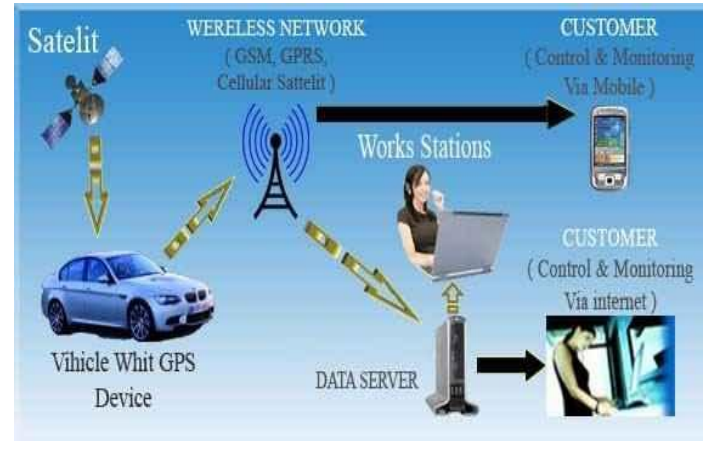

\section{Gambar 1 Sistem Komunikasi GPS ke GSM}

Untuk penentuan posisi suatu titik (station) pengamatan diperlukan data jarak dari stasiun tersebut ke beberapa satelit GPS yang diamat. Jarak tersebut tidak dapat diukur secara langsung tetapi dengan jalan mengukur misalnya waktu rambat sinyal dari satelit ke stasiun pengamat atau jumlah fase gelombang sinyal yang merupakan fungsi waktu rambat sinyal.

Penelitian ini sebenarnya sudah penulis kembangkan dan berhasil semenjak tahun 2007, namun pada dari tahun 2007 sampai tahun 2013 dikembangkan untuk kepentingan komersial sehingga saat itu belum sempat untuk publikasi. Pada penelitian ini program untuk penerimaan informasi dari GPS memang belum sampai ke pengembangan GPRS, under web dan system online. Kelebihan dari hasil penelitian ini adalah original dengan fitur local berbahasa Indonesia dan fitur tambahan yang belum dimiliki GPS tracker lainnya. 


\section{Metode Penelitian}

Metode Penelitian ini dimulai dari mengumpulkan bahan-bahan untuk membuat GPS Tracker, kemudian merakitnya dan memberikan software aplikasi, untuk menguji keakuratan dari GPS Tracker tersebut dengan cara memasukan ordinat garis lintang dan garis bujur pada peta digital yang di install di handphone, laptop ataupun alat navigasi. Untuk menuju lokasi koordinat, maka peta digital tersebut kemudian di hubungkan dengan satelit dengan GPS receiver ( Bluetooth, USB atau GPS internal) sebagai Navigasi atau penunjuk arah menuju lokasi kendaraan.

a. Bahan :

Bahan penelitian yang digunakan adalah :

a. PCB, Connector GSM Module

b. GPS Module Holux 8929

c. GSM Module SIM 300C

d. Relay \& Mic Condensor

e. ATmega 8L

f. Kabel Konektor, SIM Holde

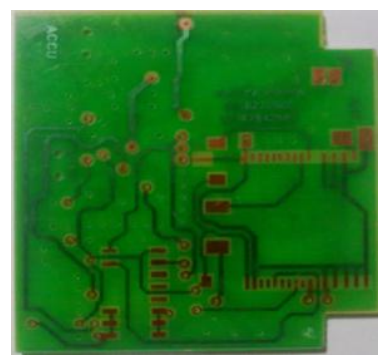

Gambar 2 PCB hasil rancangan

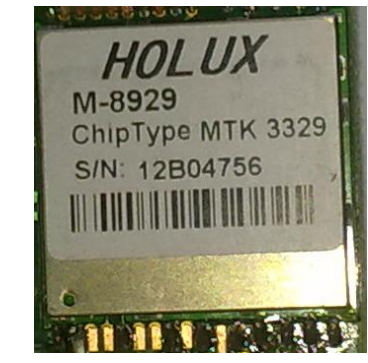

Gambar 3 GPS Module

Spesifikasi GPS Module Holux 8929:

- High sensitivity $-159 \mathrm{dBm}$

- Searching up to 32 Channel of satellites

- $\quad$ RTCM- in ready

- Built-in WAAS/EGNOS/MSAS Demodulator

- Support NMEA0183 V 3.01 data protocol

- Real time navigation for location based services

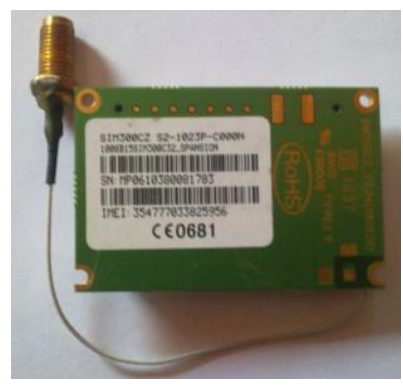

Gambar 4 GSM Module

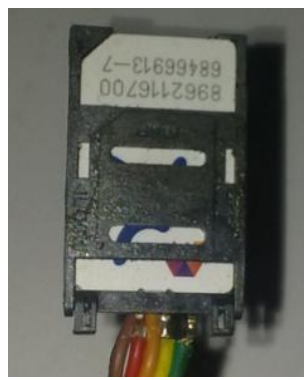

Gambar 5 SIM Holder 
Spesifikasi GSM Module SIM 300C :

- Tri-Band GSM/GPRS 900/1800/1900 $\mathrm{MHz}$

- GPRS multi-slot class 10/8

- GPRS mobile station class B

- Compliant to GSM phase 2/2+

- Class 4 (2 W @ 900 MHz)

- Class 1 (1 W@ 1800/1900MHz)

- Dimensions: $50 * 33 * 6.2 \mathrm{~mm}$

- SIM application toolkit

- Supply voltage range $3.4 \ldots 4.5 \mathrm{~V}$

- Low power consumption
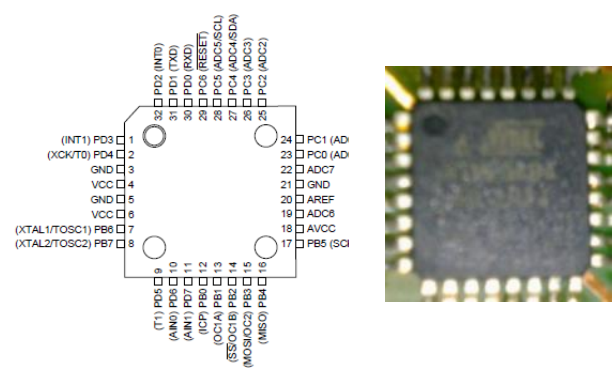

\section{Gambar 6 ATmega 8L}

2.2.Peralatan dan alat bantu
a. Solder
b. Timah/tenol
c. Handphone
d. Computer / laptop
e. Baterai Backup
f. Bluetooth GPS Receiver
g. Downloader
h. Software peta digital Garmin dan PC suite nokia

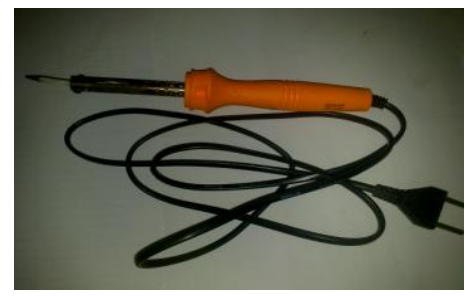

Gambar 7 Solder

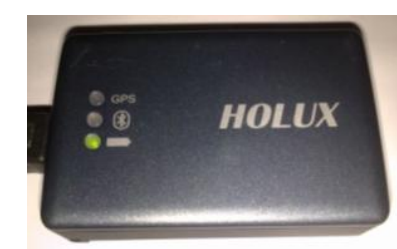

\section{Gambar 8 GPS Receiver}

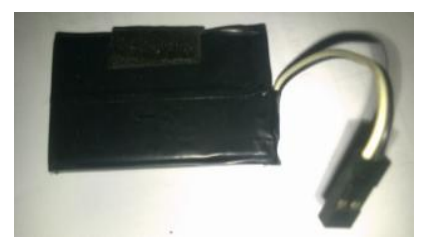

Gambar 9 Baterai Backup

\section{Hasil dan Pembahasan}

Hasil rakitan GPS tracker ini saya namakan Powertrack, terdiri dari 4 kabel output ( kabel power, kabel ground, kabel on/off dan kabel sensor) 1 kabel microphone untuk sadap, 2 konektor untuk antena GPS dan antena GSM.

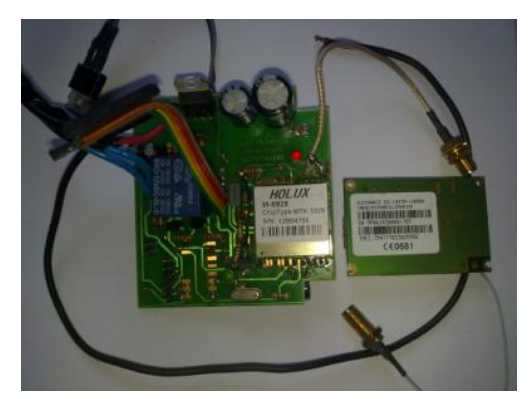

Gambar 10 Hasil Rakitan Powertrack 
Untuk pemasangannya sebagai berikut : pertama kabel ground disambungkan ke bodi, kabel on/off disambungkan power engine mobil/motor, SIM dimasukan ke SIM Holder, kedua antena GPS dan antena GSM disambungkan ke konektor Powertrack kemudian kabel power dihubungkan 12 Volt aki mobil/motor, terakhir baterai backup disambungkan ke Powertrack. Setelah selesai semua kemudian ditutup dan dibaut agar kuat dan dipasang pada tempat tersembunyi.

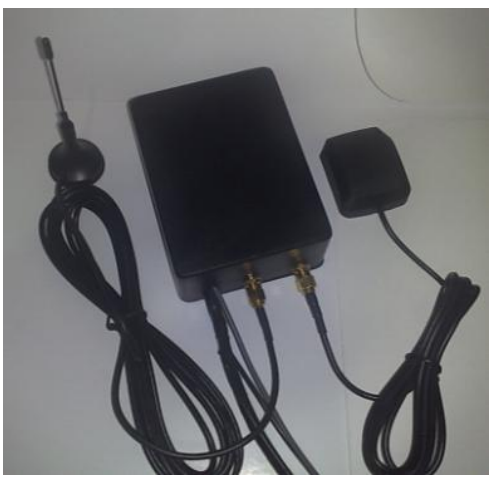

\section{Gambar 11 Produk jadi GPS Tracker Powertrack}

3.1 Cara penggunaan alat Powertrack:

I. VIA SMS :

1. SMS dari HP Simcard Master ketik : POS atau POSI Kirim Ke No.HP Mobil, akan ada balasan SMS berupa Tanggal. Jam, Kecepatan \& Posisi Mobil tersebut berdasarkan satelit garis Lintang dan Bujur misal : Lat $07^{\circ} 45.689 \mathrm{~S}$ dan Long $110^{\circ} 22.565 \mathrm{E}$ (format degree, minute, decimal). Ordinat tersebut masukan di Peta Digital Google Earth atau Peta GARMIN).

2. SMS dari HP Simcard Master ketik : OFF Kirim Ke No.HP Mobil, nanti akan ada balasan SMS berupa Informasi Mobil sudah dimatikan

3. SMS dari HP Simcard Master ketik : ON Kirim Ke No.HP Mobil, nanti akan ada balasan SMS berupa Informasi Mobil sudah dihidupkan.

4. SMS dari HP Simcard Master ketik : PUL Kirim Ke No.HP Mobil, Informasi Pulsa yg ada di Alat/Mobil)

5. SMS dari HP Simcard Master ketik : AKTIF Kirim Ke No.HP Mobil, nanti akan ada SMS otomatis jika Mobil dihidupkan (berhenti otomatis PASIF)

6. SMS dari HP Simcard Master ketik : SET 30 Kirim Ke No.HP Mobil, nanti akan ada SMS otomatis Posisi setiap 30 menit, 1 sampai 90 untuk 
berhenti

otomatis

laporannya SMS SET 0.

7. SMS dari HP Simcard Master ketik : WHERE 0818270xxx (No.HP Mobil) kirim ke 9455

Informasi berdasarkan

*BTS/Tower XL $\quad(*=j i k a$ Simcard sama2 XL dan sudah di regestrasi).

8. Ada SMS otomatis jika Alat atau Aki dilepas beserta Posisinya

II. VIA CALL :

Call dari HP Simcard Master Ke No.HP Mobil, otomatis akan terima, fungsinya untuk menyadap suara yang ada di Mobil, tetapi hasil sadap belum jernih suaranya.

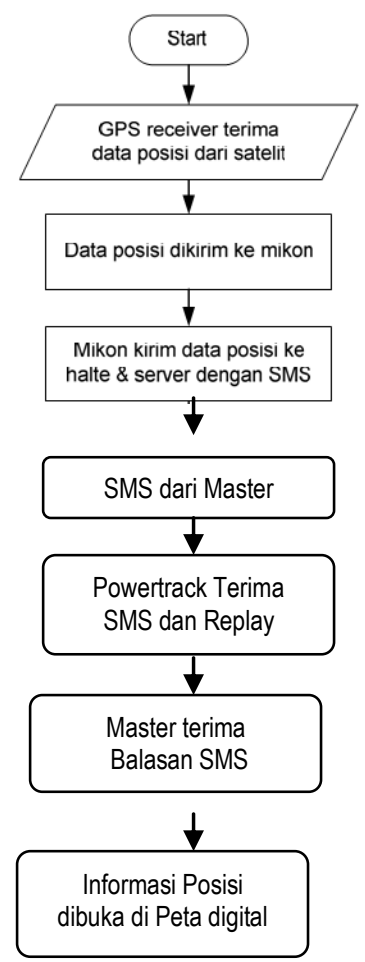

Gambar 12 Flowchart proses komunikasi

3.2 Cara mengecek ordinat posisi:

Contoh jika Powertrack dipasang di mobil, dengan menggunakan fitur AKTIF akan nomor master akan terima SMS dari Powertrack otomatis jika mesin mobil dihidupkan atau dimatikan, sehingga apabila mobil diparkir di tempat yang agak jauh pemilik mobil akan mengetahui jika ada yang mencoba menghidupkan mobil apakah itu memang akan dicuri atau mengetahui mobil akan berjalan kembali, lihat pada Gambar 13. 


\section{의 Nokia Communication Cen..}

$-\square \mid x$

From: AA1464 0514

Time: Tuesday, October 29, 2013 9:24 PM

Tolong Aku Segera!

Mesin Dihidupkan

Data Valid

290ct13 21:24

Lat :0747.1385s

Speed: $0 \mathrm{Km} / \mathrm{H}$

"POWER TRACK-Narya Prima".

\section{? 口田它}

Gambar 13 Hasil SMS otomatis jika mesin mobil dihidupkan

Begitu juga apabila pemakai mobil sudah selesai pemakaian dan mematikan mobil maka akan ada laporan bahwa mesin dimatikan dan pemilik segera mengetahui dimana terakhir mobil berhenti. Fitur ini penting karena langsung mengetahui dimana mobil menginap atau istirahat pada waktu malam hari sebagai patokan bahwa mobil istrirahat di rumah pemakai dan akan mudah mencari untuk pelacakan berikutnya.

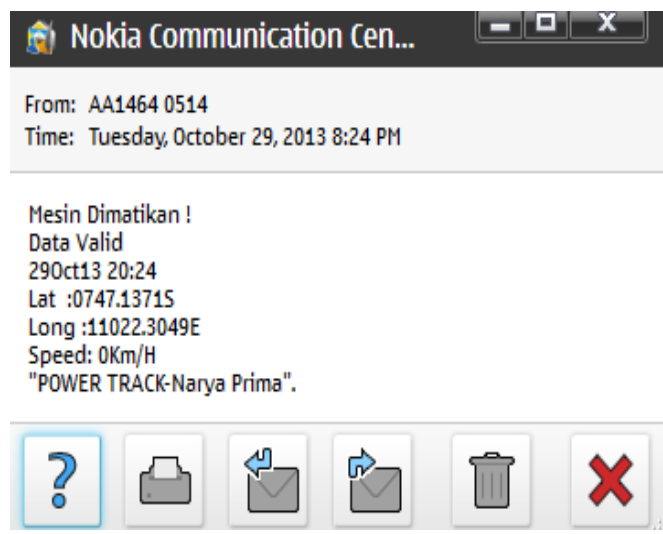

Gambar 14 Hasil SMS otomatis jika mesin mobil dimatikan

Dengan fitur SET 30 maka secara otomatis alat akan lapor kurang lebih setiap 30 menit sekali, tidak tepat 30 menit karena biasanya terkendala SMS yang tertunda karena system jaringan provider kadang ada masalah, lihat Gambar 15 dan Gambar 16.

\section{(A) Nokia Communication Cen.. \\ $=\square x$}

From: AA1464 0514

Time: Tuesday, October 29, 2013 10:03 PM

SMS posisi otomatis setiap: 30Menit

Data Valid

290ct13 22:03

Lat :0746.2795S

Long :11024.5715E

Speed: $25 \mathrm{Km} / \mathrm{H}$

"POWER TRACK-Narya Prima".

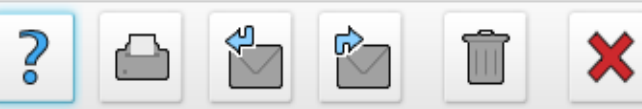

Gambar 15 Hasil SMS otomatis jika diatur waktu 30 menit

Pada saat proses pengejaran biasanya durasi waktu diperpendek agar posisi lewat SMS update dan mudah ditemukan, misalnya di SET 2 berarti otomastis akan SMS setiap 2 menit sekali.

\section{(5) Nokia Communication Cen... $\quad \square \quad \square \quad x$}

From: AA1464 0514

Time: Tuesday, October 29, 2013 10:34 PM

Data Valid

290ct13 22:34

Lat :0747.96865

Long :11022.3250E

Speed: $0 \mathrm{Km} / \mathrm{H}$

"POWER TRACK-Narva Prima".

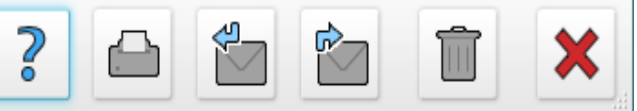

Gambar 16 Hasil SMS otomatis 30 menit dengan selisih 31 menit

Untuk mengetahui posisi mobil dalam kesempatan tertentu atau saat tertentu ingin mengetahui langsung maka dapat menggunakan fitur POS maka saat itu 
juga Powertrack akan mengirim posisi, hasilnya sama seperti pada Gambar 17.

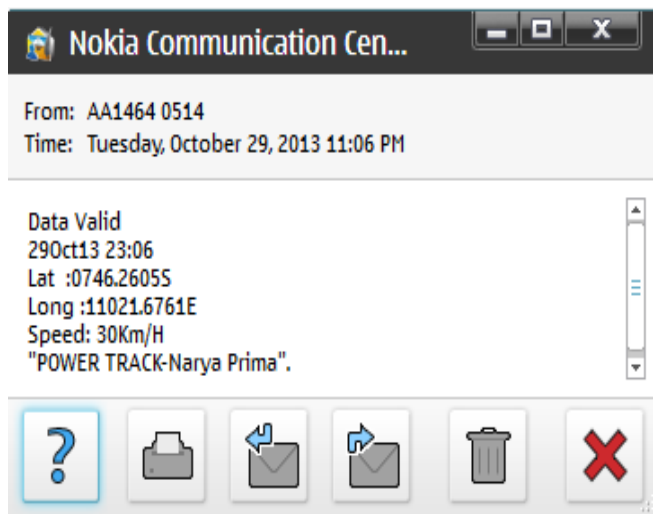

Gambar 17 Hasil SMS POS pada saat kecepatan 30km/jam

Untuk mendapatkan mendapatkan balasan dari Powertrack yang berupa weblink dan bisa langsung dibuka di google maps dengan lewat jalur online internet maka dapat menggunakan fitur POSI, dengan hasil SMS seperti pada Gambar 18 dan Gambar 19.

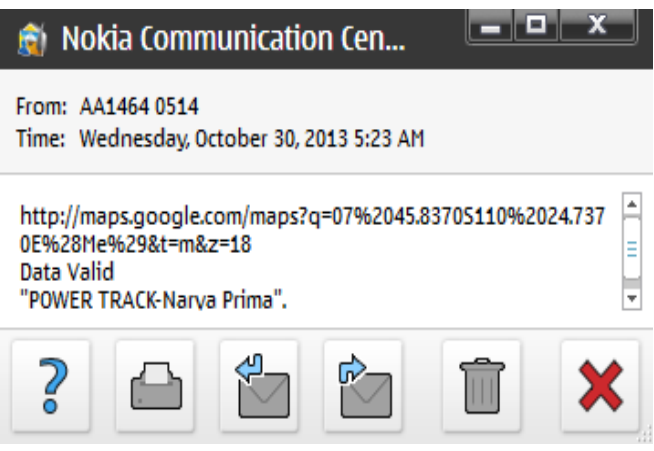

Gambar 18 Hasil SMS POSI berupa link website

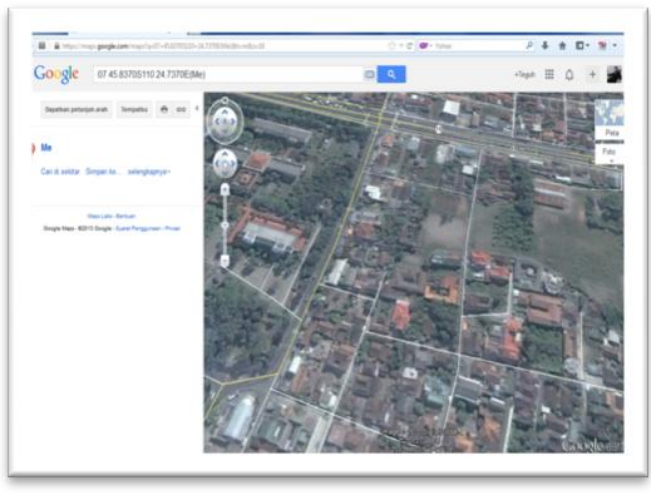

\section{Gambar 19 Hasil openlink website} google maps

Apabila posisi mobil sudah diketahui adakalanya pemilik mobil ingin mematikan mobil atau dalam kondisi tertentu misalkanparkir ditepi jalan dan agar mobil tidak bisa di jalankan maka biasanya mobil dimatikan sistem enginenya dan ini dapat menggunakan fitur OFF maka secara otomatis akan dapat balasan seperti pada Gambar 20, dan untuk menghidupkan kembali dapat menggunakan fitur $\mathbf{O N}$ maka secara otomatis akan dapat balasan seperti pada Gambar 21.

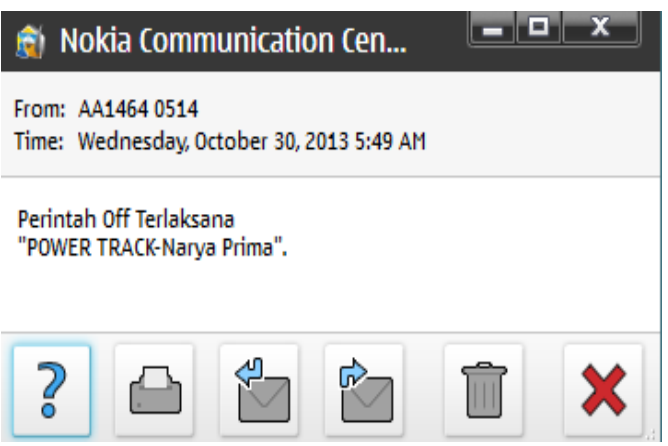

Gambar 20 Hasil SMS OFF

Pada saat melakukan pengejaran melakukan perintah OFF haruslah sangat hati-hati karena berkaitan keamanan 
pengendera mobil sendiri ataupun pengendara lain karena jika di OFF kan secara mendadak mobil akan mogok.

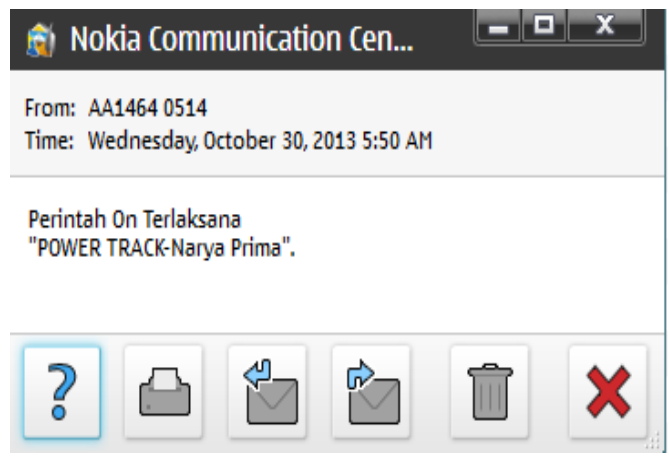

Gambar 21 Hasil SMS ON

Saat ini perkembangan informasi GPS sangat cepat sehingga dalam kasus tertentu ada beberapa pencuri mobil atau penggelap mobil sudah mengetahui keberadaan alat GPS tracker seperti Powertrack terdapat dimobil sehingga mereka berusaha mencari untuk dirusak ataupun dihancurkan. Dalam tahap ini biasanya meraka mencoba terlebih dahulu mematikan sumber power yaitu aki, sehingga dengan adanya baterai backup pada Powertrack ini memungkinkan secara otomatis akan mengirim SMS ke nomor master seperti pada Gambar 22. Sehingga segera setelah mendapatkan SMS itu pemilik mobil segera menuju posisi yang telah dikirimkan tersebut dengan alat navigasi.
From: $+62819317513^{\circ}$

Time: Thursday, Octc .........3 5:51 AM

Tolong Aku Segera!

Aki dicabut!

Data Valid

310ct13 05:51

Lat :0746.51375

Long : $11022.2573 \mathrm{E}$

Speed: $0 \mathrm{Km} / \mathrm{H}$

Speed: $0 \mathrm{Km} / \mathrm{H}$

"POWER TRACK-Narya Prima".

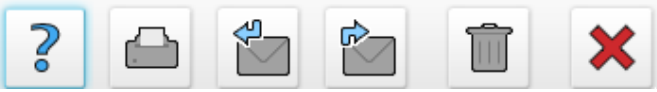

Gambar 22 Hasil SMS otomatis jika power hilang

Dalam beberapa kali percobaan dan pemakaian Powertrack ini bekerja sangat akurat, artinya keberhasilan untuk melacak posisi mendekati $100 \%$. Namun ada kalanya posisi yang diharapkan tidak akurat, seperti nampak pada Gambar 23, ada balasan yang menggambarkan data Unvalid sehingga tidak akurat, itu ada beberapa penyebabnya diantaranya :

1. Posisi mobil didalam basemant gedung dengan beberapa lantai sehingga sinyal satelit tidak tembus.

2. Antena GPS yang rusak atau konektornya tidak kencang.

3. Solderan dari GPS module ada yang kendor karena sudah beberapa kali pemakaian.

4. Komponen GPS module sudah lemah sehingga perlu diganti lagi. 


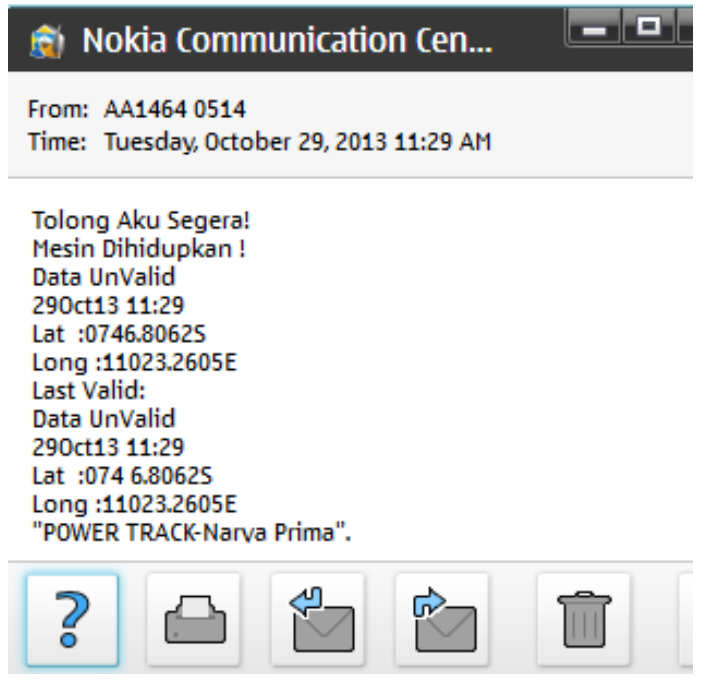

\section{Gambar 24 Hasil SMS ordinat unvalid} atau tidak akurat

Pada kondisi tersebut untuk membantu keberadaaan posisi dapat menggunakan bantuan informasi fitur provider tertentu, misalnya dengan provider XL ada bantuan mencari posisi dengan fitur Where $\mathbf{R} \mathbf{U}$ dengan catatan sudah diregistrasi terlebih dahulu sebelumnya pada saat pemasangan Powertrack dengan informasi misalnya, "nomor 0818... disekitar jalan kaliurang, sleman, Yogyakarta ......".

3.3 Cara mengecek posisi dengan peta digital:

Salah cara untuk mengecek posisi dan untuk memasukan ordinat dari SMS adalah menggunakan Peta digital GARMIN yang sudah di install di handphone atau windows, seperti pada gambar 24 .

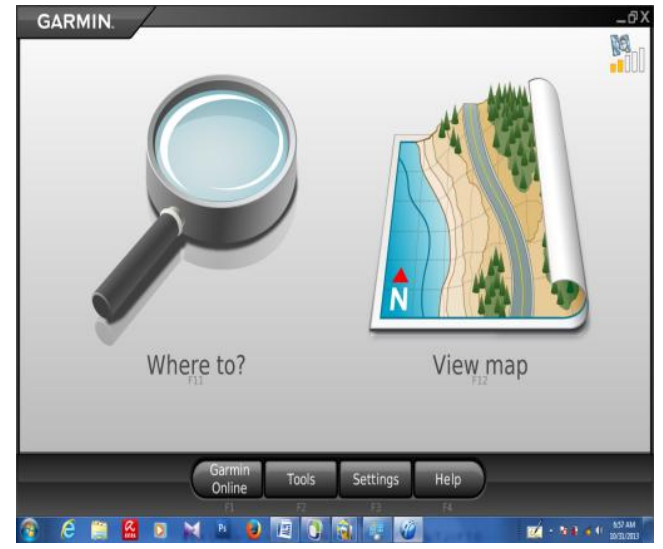

Gambar 24 Peta digital GARMIN

Kemudian untuk memasukannya pada fitur position seperti pada Gambar 25 ini, untuk melihat posisi point dipeta tinggal klik next saja bisa seperti pada Gambar 26.

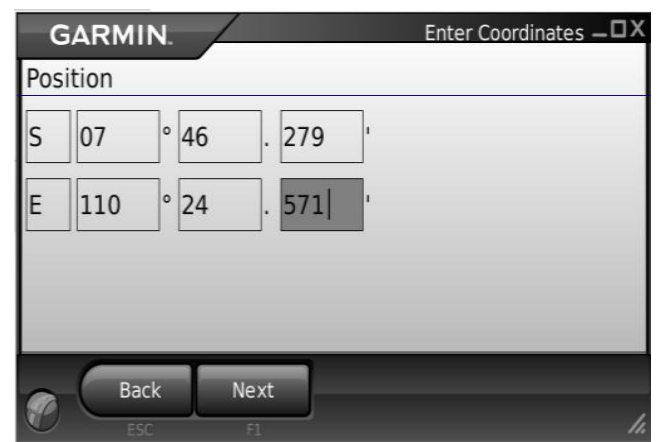

Gambar 25 Memasukan ordinat Powertrack

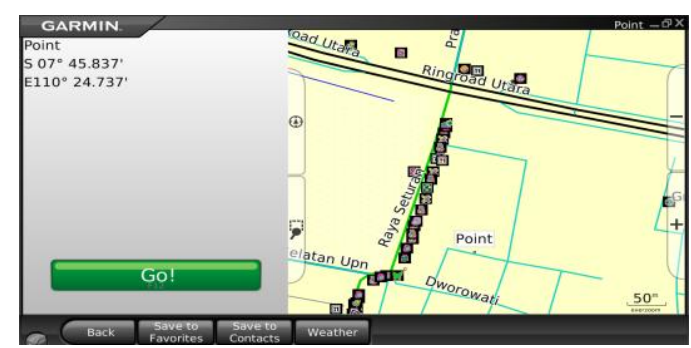

Gambar 26 Posisi point mobil di Peta GARMIN

Untuk memastikan keberadaaan posisi mobil dapt langsung menuju ke titik point 
tersebut dengan catatan sinyal dari satelit didalam software GARMIN tersebut sudah valid atau akurat, itu bisa ditandai dengan gambar kekuatan sinyal GPSnya dan muncul 3D GPS Location, seperti Nampak pada Gambar 27.

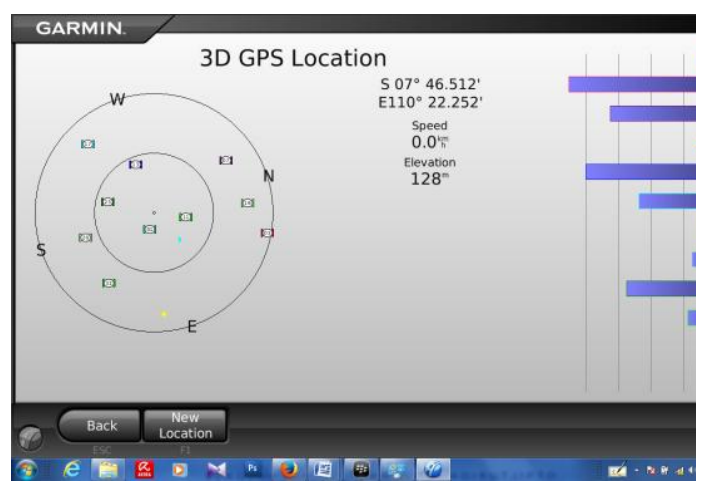

\section{Gambar 27 Kekuatan sinyal GPS pada Peta GARMIN}

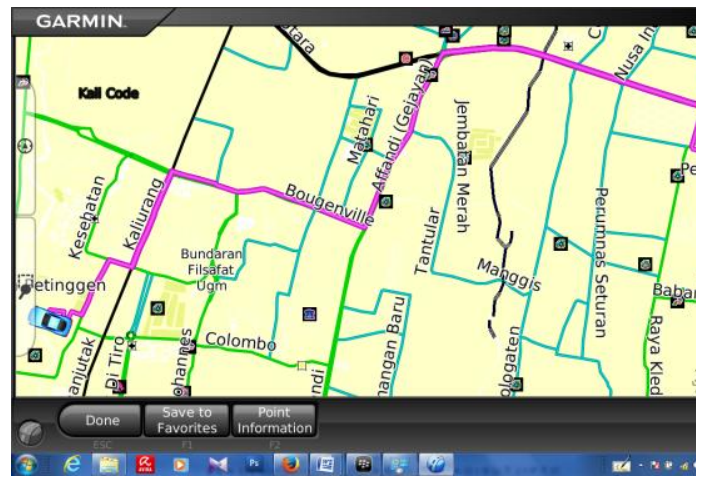

Gambar 28 Jalur menuju lokasi dengan Peta GARMIN

Jika sudah dipastikan sinyal bagus maka tinggal menekan tombol GO untuk menuju lokasi dengan tambahan suara berbahasa Indonesia, seperti terlihat pada Gambar 28.

Dari beberapa kasus pelacakan ini posisi mobil diketemukan dengan cepat dan tepat, hanya saja ketika mobil di simpan dalam garasi yang tertutup cara memastikannya dengan remote control bawaan mobil ataupun terpaksa menanyakan langsung kepada pemilik garasi tersebut.

\section{KESIMPULAN}

Dari keseluruhan pembahasan dalam penelitian ini, dapat disimpulkan bahwa aplikasi GPS Powertrack pada sistem monitoring kendaraan dapat diterapkan dengan baik karena data posisi koordinat dari satelit GPS dapat terdeteksi dengan baik disepanjang jalur yang dilalui mobil selama ada sinyal provider. Pengiriman data koordinat posisi mobil secara terus menerus bisa dilakukan dengan pengiriman SMS otomatis dengan durasi sesuai kebutuhan, sehingga mempunyai rekaman perjalanan mobil. Powertrack ini dapat dijadikan sistem keamanan untuk menggagalkan pencurian dan pemantauan kepergian keluarga yang perlu perhatian khusus.

\section{SARAN}

Penelitian ini memang belum mengakomodir kebutuhan pemantaun lewat GPRS dan website yang tersimpan di server sehingga masih dimungkinkan untuk penelitian lebih lanjut. Penelitian mungkin masih banyak kekurangan, sehingga saran yang membangun sangat penulis butuhkan. 


\section{DAFTAR PUSTAKA}

Arfian Eko Nugroho, D, 2008, Pengenalan Alat Ukur GPS.

Endah, W. Rachma, P. Rian, W. Susilo, U. Umuhani, I.W.S. Wicaksana, Perbandingan Transfer Rate GSM pada Handphone sebagai Device Access dan Handpone sebagai Modem, http://openstorage.gunadarma.ac.id/ m wiryana/KOMMIT/per-artikel/01-03013.pdf, 2011.

Ernastuti Muhammad Bintang, 2010, Sistem Pelacak Rute Kendaraan Dengan Teknologi Gps Dan Gprs, Pusat Studi Komputasi Matematika Universitas Gunadarma.

Gregory T. French, 1996, Understanding The GPS , First Edition, GeoResearch, Inc, ISBN: 0-9655723O-7

Pebrianto Budi Prabowo, D. C. 2010. Rancang Bangun Aplikasi Pemantau Penyelewengan Kendaraan Dinas Dengan Menggunakan Modul Gps.

Sunyoto, Pemanfaatan Modul GPS Receiver dan Telepon Selular untuk Wide Area Vehicle Tracking, Prosiding Seminar Nasional Teknologi (SNT 2007), Jakarta, 2007.

Z.A. Abidin, Penentuan Posisi GPS dan Aplikasinya, Pranya Paramita, Jakarta, 2007, p.101.

http://melacak.net/apa-itu-gpstracker.html.

http://gpsonlineid.com/gps-pelacak-untukpemantauan-aset-dan-perlindunganyang-lebih-baik/ 